\title{
Large Banks of Negative Differential Resistance Nonlinear Loads: A Hidden Threat to Power System Quality
}

\author{
MAHMOOD AHMAD*, SAJJAD ALI**, TAHIR IZHAR**, AND MUHAMMAD MANSOOR*** \\ RECEIVED ON 30.08.2016 ACCEPTED ON 21.02.2017
}

\begin{abstract}
DSM (Demand Side Management) is a short term and comparatively low cost solution for energy starved countries. Replacement of IB (Incandescent Bulbs) with CFL (Compact Fluorescent Lamps) has proved its success throughout the world. The same solution, at larger scale, was proposed to Pakistan to mitigate power shortage on short term basis. Accordingly in year 2008, ADB (Asian Development Bank) conducted a study and it was found that replacement of conventional IB with 30 million CFL will result into series of benefits for the stake holders and above all the Environment. The study, unfortunately didn't take enough consideration of effect of CFLs on the power system being nonlinear device and so the power quality issues remained a secondary consideration. The focus of this paper remains on the effect of such non-linear load on consumers, it also envisages the erratic behaviour of such large penetration of CFLs on direct single phase, three phase, digital as well as electromechanical energy meters, under different loading conditions e.g. resistive load, SMPS (Switch Mode Power Supply), half and full-wave rectifiers. It also reflects harmonic pollution caused by CFLs, their effect on power system quality and the registration ability of electromechanical as well as digital energy meters. To this end Harmonic spectrum was recorded up to the 31st harmonic.
\end{abstract}

\section{INTRODUCTION}

$\mathrm{P}$ akistan will replace 30 million IB with CFL for residential consumers spread throughout the country in ten utilities. Energy efficiency is being considered as least cost remedy to address current power shortages in Pakistan. This demand side management program is the biggest of its kind and so unique throughout the world.

PEPCO (Pakistan Electric Power Company) distributed two CFLs to each domestic consumer throughout the country, without any cost impact to the customer and in exchange of two IB.

Impact assessment study was carried out by M/s Haggler and Bally of Pakistan. It was observed that this programme will result in saving of approximately 2000 GWhs. Revenues of CDM (Clean Development Mechanism) under this program amount to US \$ 32 million by the end of year 2018 to the government.

Corresponding Author (E-Mail: sajjadabdul33@gmail.com)

* National Transmission and Dispatch Company, Lahore.

** Department of Electrical Engineering, University of Engineering \& Technology, Lahore.

*** $\quad$ CAPER, Faculty of Engineering, University Putra, Malaysia.

Mehran University Research Journal of Engineering \& Technology, Volume 37, No. 1, January, 2018 [p-ISSN: 0254-7821, e-ISSN: 2413-7219] 
For the purpose of impact assessment on overall power system, test bench were developed, to feed CFLs through electromechanical and digital meters and to add resistive and nonlinear load with different combination of CFLs. MicroVIP and Fluke 43-B, power Quality Meter were the main instruments to record different readings.

It was observed that although, the effect of individual CFL is negligible however, large penetration of CFLs causes measureable harmonic distortion [1]. The focus of this paper is to study the effect of higher order harmonics on the behaviour of energy measurement mechanism of energy meters. It is needless to mention the effects of harmonics on excessive heating of distribution transformers, increase loading on LT (Low Tension) conductors, damage of capacitor banks, reduction in the designed life of energy meters, maloperation of protective relays that require real time adaptive protection settings to operate properly [2], increase system losses and reduced efficiency of rotating machines etc. [3].

\section{EXPERIMENTAL ARRANGEMENT USED}

Five test benches each for 28 CFLs (CFL specifications are shown in Fig. 1 and Table 1) were fabricated for the subjected study. The five test benches, in parallel, were fed through three phase digital, single phase digital and single phase electromechanical energy meters by connecting them in series with the supply.

Arrangement used to investigate the effect of harmonics on measurement of the energy meter.

The experimentation was started from two CFLs and was gradually increased to 28, 56, 99 and 111 CFLs. For detailed study of harmonics spectrum and their impact on power system quality, FLUKE 43B \&MicroVIP Power Quality Analysers were used. It was found that CFLs draw current which is rich in odd harmonics (3rd, 5th, 7th, 9th, 11th, and 13th) out of total spectrum of 31 harmonics levels. Fig. 2 is the current drawn by two CFLs and Fig. 3 is the current harmonic spectrum for these CFLs.

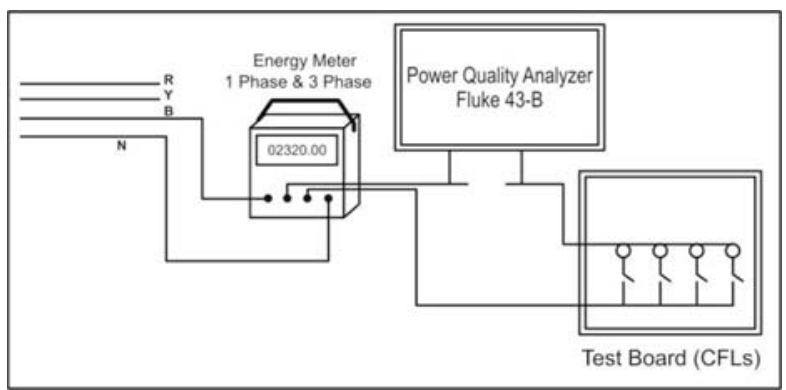

FIG. 1. EXPERIMENTAL ARRANGEMENT

TABLE 1. CFL TECHNICAL DATA

\begin{tabular}{|c|c|}
\hline Bran & Philips \\
\hline Rated Power & 23 Watt \\
\hline Rated Voltage & $220-240$ Volt \\
\hline Frequency & $50-60 \mathrm{~Hz}$ \\
\hline Rated Current & $165 \mathrm{~mA}$ \\
\hline Lux & 1450 Lumens \\
\hline Efficiency & $66 \mathrm{Lm} /$ Watt \\
\hline
\end{tabular}
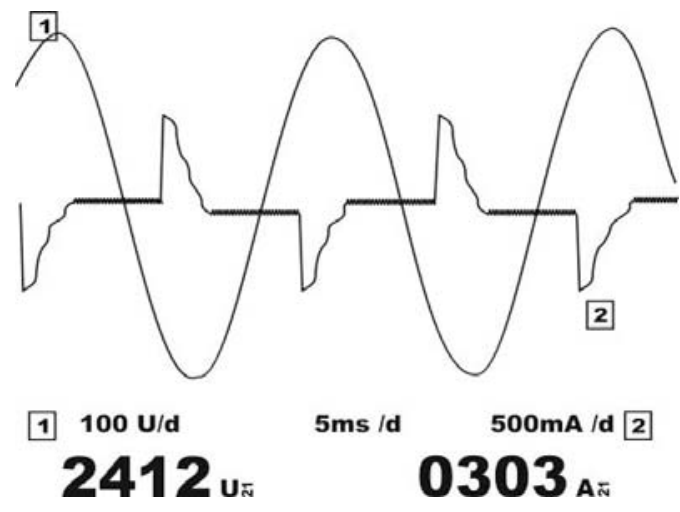

FIG. 2. CURRENT ABSORBED BY TWO CFLS

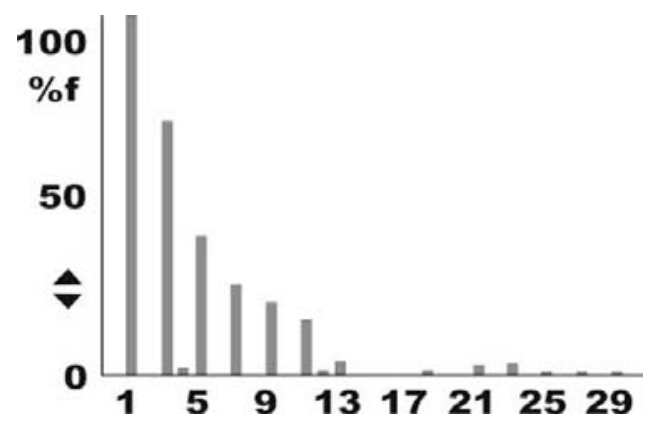

FIG. 3. HARMONICS SPECTRUM OF TWO CFLS 
Table 2 relative harmonic distortion, current level and phase shifts of individual components up to 31st component based on FLUKE 43B experimental results.

Lower odd harmonics are dominating and they contribute more towards THD (Total Harmonic Distortion).

Current equation for Fourier analysis based on FLUKE 43B measurements for cross examination are as follows:

$\mathrm{I}_{1}=0.21 \times 2 \sqrt{2} \times \sin (\mathrm{w} * \mathrm{t})$

$I_{3}=0.16 \times 2 \sqrt{2} \times \sin \left(3 \omega t-+168 \frac{\pi}{180}\right)$

$I_{5}=0.08 \times 2 \sqrt{2} \times \sin \left(5 \omega t+3 \frac{\pi}{180}\right)$

$I_{7}=0.05 \times 2 \sqrt{2} \times \sin \left(7 \omega t-163 \frac{\pi}{180}\right)$

$I_{9}=0.05 \times 2 \sqrt{2} \times \sin \left(9 \omega t+34 \frac{\pi}{180}\right)$

$$
\begin{aligned}
& I_{11}=0.04 \times 2 \sqrt{2} \times \sin \left(11 \omega t-131 \frac{\pi}{180}\right) \\
& I_{13}=0.02 \times 2 \sqrt{2} \times \sin \left(13 \omega t+36 \frac{\pi}{180}\right) \\
& I_{15}=0.0 \times 2 \sqrt{2} \times \sin \left(15 \omega t-84 \frac{\pi}{180}\right) \\
& I_{17}=0.0 \times 2 \sqrt{2} \times \sin \left(17 \omega t+148 \frac{\pi}{180}\right) \\
& I_{19}=0.0 \times 2 \sqrt{2} \times \sin \left(19 \omega t-25 \frac{\pi}{180}\right) \\
& I_{21}=0.0 \times 2 \sqrt{2} \times \sin \left(21 \omega t-82 \frac{\pi}{180}\right) \\
& I_{23}=0.01 \times 2 \sqrt{2} \times \sin \left(23 \omega t+112 \frac{\pi}{180}\right) \\
& I_{25}=0.0 \times 2 \sqrt{2} \times \sin \left(25 \omega t-104 \frac{\pi}{180}\right)
\end{aligned}
$$

TABLE 2. RELATIVE HARMONIC DISTORTION

\begin{tabular}{|c|c|c|c|c|}
\hline No. & Description & $\begin{array}{c}\text { Individual Harmonic Distortion } \\
\text { IHD w.r.t Fundamental } \\
\text { Component (\%) }\end{array}$ & $\begin{array}{c}\text { Current Magnitude } \\
\text { (A) }\end{array}$ & $\begin{array}{c}\text { Phase Shift } \\
\text { (Degrees) }\end{array}$ \\
\hline 1. & Fundamental Component & 100 & 0.21 & 0 \\
\hline 2. & 3rd Component & 71.9 & 0.16 & 3 \\
\hline 3. & 5th Component & 39.8 & 0.05 & -163 \\
\hline 4. & 7th Component & 26.7 & 0.05 & 34 \\
\hline 5. & 9th Component. & 23.3 & 0.04 & -131 \\
\hline 6. & 11th Component & 18.9 & 0.02 & 36 \\
\hline 7. & 13th Component & 11.2 & 0.0 & -84 \\
\hline 8. & 15th Component & 1.1 & 0.0 & 148 \\
\hline 9. & 17th Component & 1.1 & 0.0 & -25 \\
\hline 10. & 19th Component & 1.1 & 0.0 & -82 \\
\hline 11. & 21st Component & 1.1 & 0.01 & 112 \\
\hline 12. & 23rd Component & 3.5 & 0.0 & -104 \\
\hline 13. & 25th Component & 1.2 & 0.0 & 156 \\
\hline 14. & 27th Component & 1.1 & 0.01 & -47 \\
\hline 15. & 29th Component & 3.5 & 0.0 & 167 \\
\hline 16. & 31st Component & & & \\
\hline
\end{tabular}

Mehran University Research Journal of Engineering \& Technology, Volume 37, No. 1, January, 2018 [p-ISSN: 0254-7821, e-ISSN: 2413-7219] 


$$
\begin{aligned}
& I_{27}=0.0 \times 2 \sqrt{2} \times \sin \left(27 \omega t+156 \frac{\pi}{180}\right) \\
& I_{29}=0.01 \times 2 \sqrt{2} \times \sin \left(29 \omega t-47 \frac{\pi}{180}\right) \\
& I_{31}=0.0 \times 2 \sqrt{2} \times \sin \left(31 \omega t+167 \frac{\pi}{180}\right) \\
& I_{\text {total }}=\sum_{i=0}^{N} I_{i}
\end{aligned}
$$

\section{MODEL VERIFICATION ON MATLAB}

RMS (Root Mean Square) value of current was calculated by incorporating individual harmonic contribution. Sampling frequency was $5000 \mathrm{~Hz}$. Current waveform drawn by two CFLs and the fundamental component were plotted for one time period i.e. 1/50.03 $\sim 0.02$ s. Fig. 4 shows the simulated current waveform. Harmonic spectrum for first 31 harmonic components was drawn using FFD (Fast Fourier Decomposition). It is plotted with respect to the fundamental component. Figs. 5-6 gives the harmonic spectrum for 31 components. The simulated results are approximately same as experimental results with small errors in individual harmonic distortion.

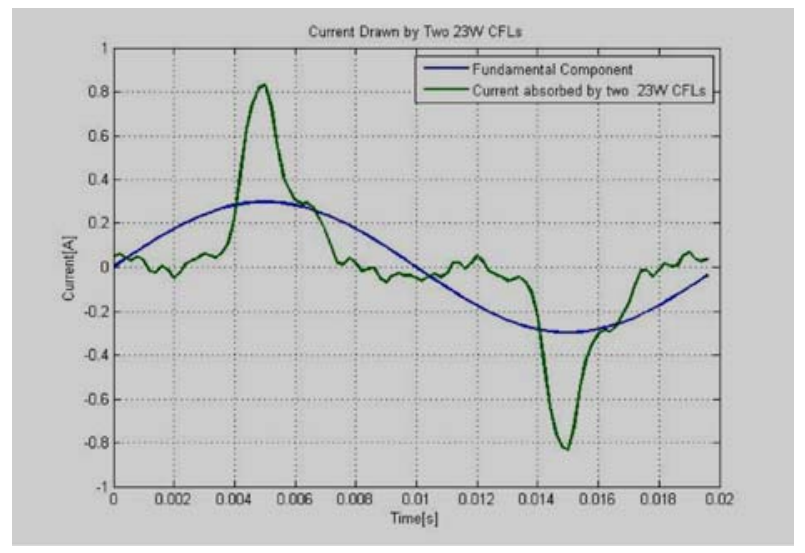

FIG. 4. SIMULATED CURRENT WAVEFORM FOR TWO CFLS

\section{COMPACT FLUORESCENT LAMP MODELS}

CFL mathematical and software models have been investigated for simulating large penetration and the harmonic distortion associated therewith. In this regard, literature reviewed shows varied approach towards achieving equivalent behaviour from circuits composed of simple passive circuit elements and dependent current sources, on an individual and a macro scale.

Eltamaly [4] has modelled an individual CFL unit in PSIM (Physical Security Information Management) that uses a current dependent current source along with additional components to simulate CFL behavior such that it can interact with other components of the power system, thus

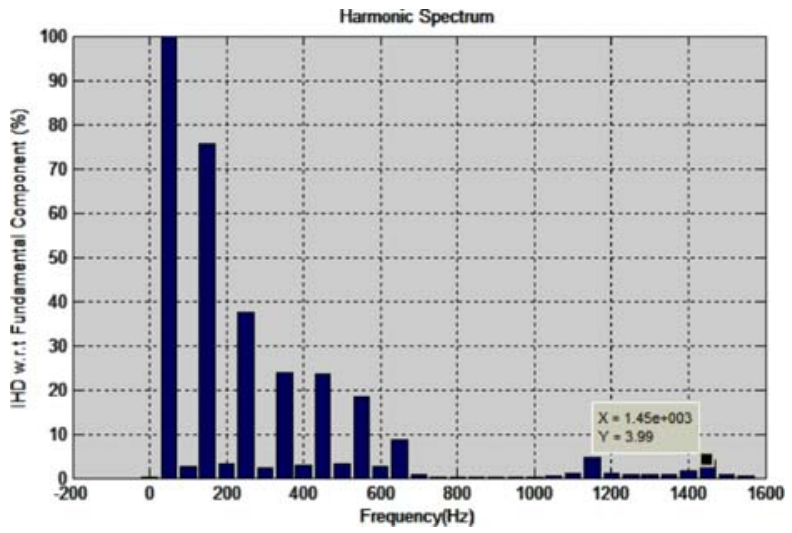

FIG. 5. HARMONIC SPECTRUM FOR TWO CFLS

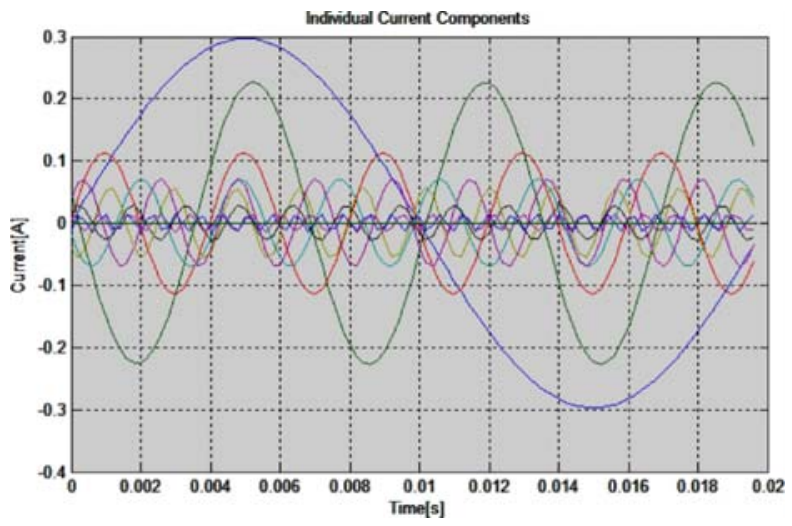

FIG. 6. INDIVIDUAL HARMONIC COMPONENTS

Mehran University Research Journal of Engineering \& Technology, Volume 37, No. 1, January, 2018 [p-ISSN: 0254-7821, e-ISSN: 2413-7219] 
presenting an insightful picture. He has further attempted to use this model in predicting the harmonic distortion levels created by a large penetration of CFL lamps on power distribution network.

Molina and Sainz [5] have presented a simplified model of CFL lamps with a single phase rectifier bridge, equivalent resistance and capacitance. The inverter circuit inside the CFL has been modelled as an equivalent resistance. The paper reviews detailed mathematical process to calculate values of equivalent passive elements.

Nohra et. al. [6] studied the impact on power quality for increased use of compact fluorescent lamps in conventional distribution power systems. Based on the experimental values taken from FLUKE 41B PQ (Power Quality) analyser, they developed a mathematical model for 23W CFL and verified the results on MATLAB simulation.

\section{RESULTS}

THD increases with the increase in number of CFLs. Figs. 7-10 shows the current harmonic spectrum for 28, 56, 99 and 111 CFLs respectively. Fig. 11 shows the harmonic spectrum for 8 CFLs with half wave rectifier. THD w.r.t fundamental current was recorded up to $189 \%$. Even as well as odd harmonics are present. Fig. 12 shows the current harmonic spectrum with full wave rectifier. THD w.r.t fundamental current was 153\%. Current is rich in odd harmonics only.

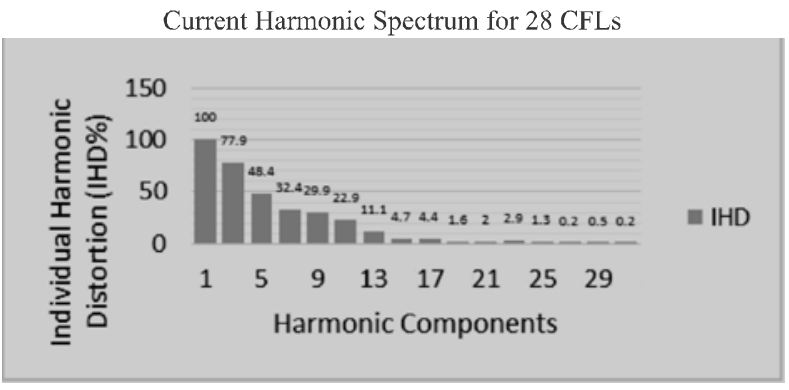

FIG. 7. CURRENT HARMONIC SPECTRUM (28 CFLS)

\section{VERIFYING ENERGY METER REGISTRATION MECHANISM ACCURACY}

To evaluate the efficiency of the registration mechanism of the said energy meters FLUKE 43-B was taken as a standard. The experiment was carried out for 40 minutes with 28 CFLs, 23 watt each having a total rated power of $0.644 \mathrm{KW}$. Initial and final readings of energy meters were noted. The standard value was compared with the readings recorded by energy meters which showed significant deviation especially in case of

Current Harmonic Spectrum for 56 CFLs

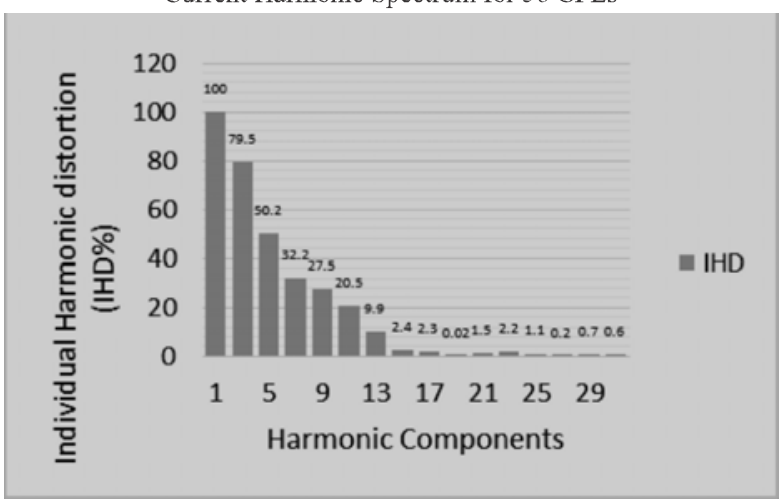

FIG. 8. CURRENT HARMONIC SPECTRUM (56 CFLS)

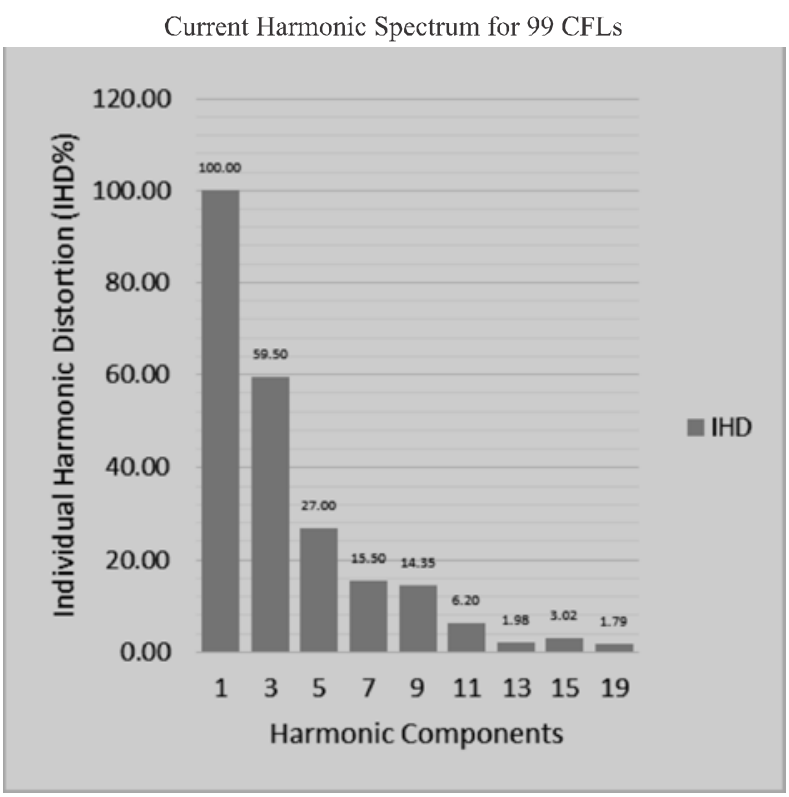

FIG. 9. CURRENT HARMONIC SPECTRUM (99 CFLS)

Mehran University Research Journal of Engineering \& Technology, Volume 37, No. 1, January, 2018 [p-ISSN: 0254-7821, e-ISSN: 2413-7219] 
electromechanical energy meter. Tables 3-4 and Fig. 13 shows the energy meters deviation from FLUKE-43B reading for 28 and 56 CFLs, respectively.

Current Harmonic Spectrum for 111 CFLs

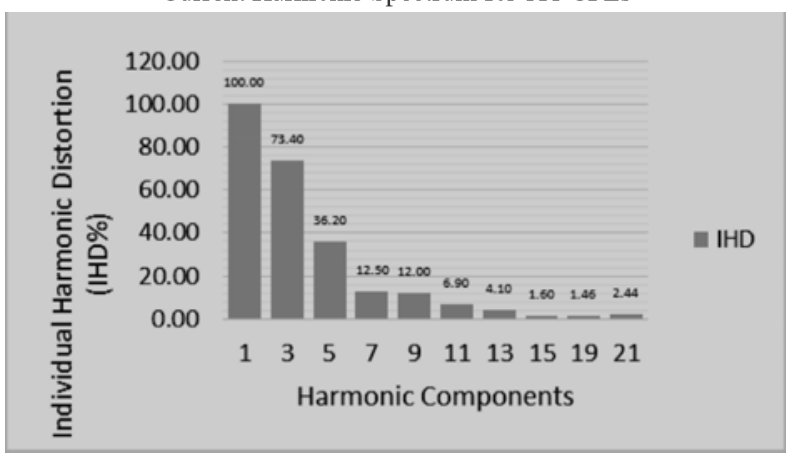

FIG. 10. CURRENT HARMONIC SPECTRUM (111 CFLS)

Current Harmonic Spectrum with Halfwave Rectifier

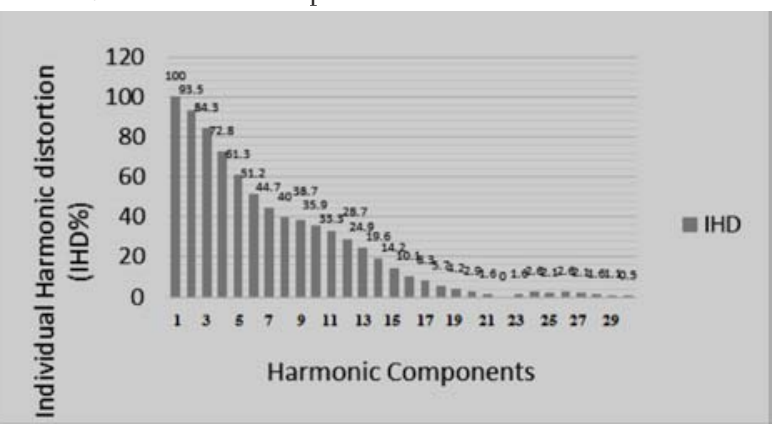

FIG. 11. CURRENT HARMONIC SPECTRUM (8 CFLS) WITH HALF WAVE RECTIFIER
Results tabulated in Tables 3-4 clearly depicts inability of prevalent electromechanical and digital meters to record energy in harmonic rich environment.

Current Harmonic Spectrum with Fullwave Rectifier

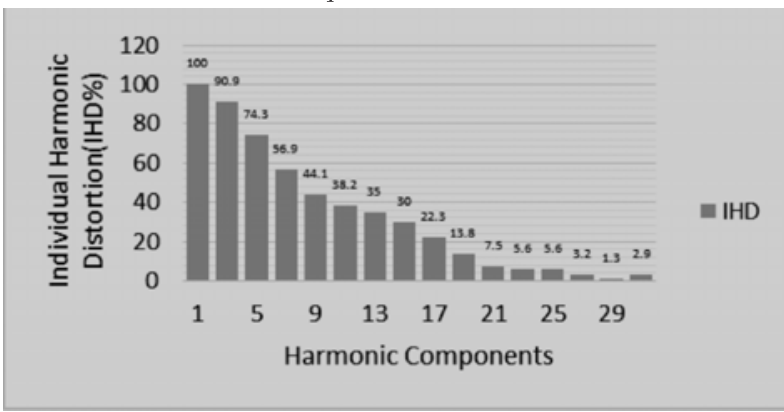

FIG. 12. CURRENT HARMONIC SPECTRUM (8 CFLS) WITH FULL WAVE RECTIFIER

THD Vs No. of CFLs

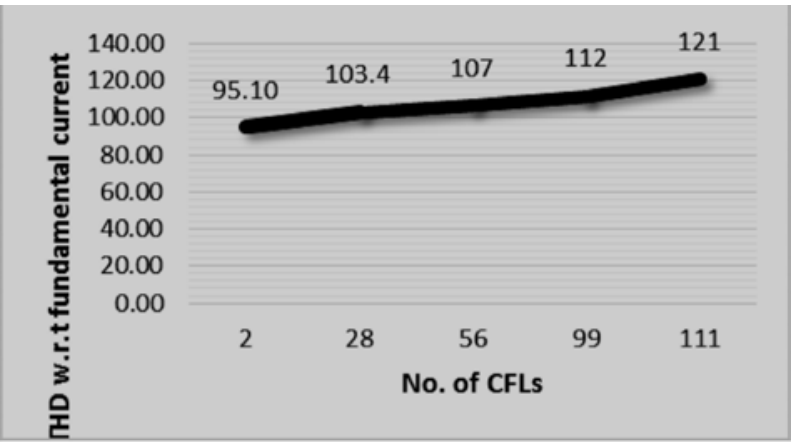

FIG. 13. INCREASE IN THD WITH THE INCREASE IN CFLS

TABLE 3. ENERGY METERS DEVIATION FROM STANDARD VALUE FOR 28 CFLS

\begin{tabular}{|c|c|c|c|}
\hline Description & PEL Digital Meter & SB Electromechanical Meter & Fluke 43B \\
\hline Units consumed & 0.4 KWh & $0.35 \mathrm{KWh}$ & $0.44 \mathrm{KWh}$ \\
\hline \multicolumn{5}{|c|}{ Taking Fluke 43B as standard } & \\
\hline & Records 9\% less energy & Records 20.4\% less energy & \\
\hline
\end{tabular}

TABLE 4. ENERGY METERS DEVIATION FROM STANDARD VALUE FOR 56 CFLS

\begin{tabular}{|c|c|c|c|c|}
\hline Description & PEL Digital Meter & SB Electromechanical Meter & Fluke 43B & 3 Phase Digital Meter \\
\hline Units consumed & 0.8 KWh & 0.75 KWh & $0.873 \mathrm{KWh}$ & $1 \mathrm{KWh}$ \\
\hline \multicolumn{5}{|c|}{ Taking Fluke 43B as standard } \\
\hline \multicolumn{5}{|c|}{ Records 14.54\% more energy } \\
\hline
\end{tabular}

Mehran University Research Journal of Engineering \& Technology, Volume 37, No. 1, January, 2018 [p-ISSN: 0254-7821, e-ISSN: 2413-7219] 
The results shown in Tables 3-4 necessitates alternative power quality monitoring and control and simplified PQ informative assessment in smart meters [7].

Transfer from incandescent lamp to CFL shall reduce electricity load on the network particularly in peak hours. This reduction in electricity usage shall not only reduce greenhouse gases emissions but also electricity consumer will get financial relief. The reduction in electricity load and consequent monetary benefit are coming at the cost of reduced power quality, health and environment issues [8]. Incandescent bulb being resistive in nature doesn't draw or provide reactive power. On the contrary CFL has capacitive characteristic behaviour. Power electronics based loads are source of harmonics and these harmonics cause an effect on reactive power and power factor measurement [9].

\section{CONCLUSION}

It was seen that current THD increases with the increase in number of CFLs. The increase in THD with the increase in CFLs. It was further verified that the CFLs affect the accuracy of energy meters. The meter which were calibrated on +/- 0 accuracy their reading error was beyond BSS limits so in case where meters became slow or the utilities are the sufferer and where the energy meters became fast the consumers were the sufferer. More importantly the slogan of energy saving was nullified due to erratic behaviour.

\section{ACKNOWLEDGEMENT}

The authors would like to pay its gratitude to the PostGraduate Research Centre, University of Engineering \& Technology, Lahore, Pakistan, for their continuous support all along this research work.

\section{REFERENCES}

[1] Jabbar, R.A., Al-Dabbagh, M., Muhammad, A., Khawaja, R.H., Akmal, M., and Arif, M.R., "Impact of Compact Fluorescent Lamp on Power Quality”, Power Engineering Conference, Australasian Universities, 2008.

[2] Ariff, M.A.M., and Pal, P.C., "Adaptive Protection and Control in the Power System for Wide-Area Blackout Prevention”, IEEE Transactions on Power Delivery, Volume 31, No. 4, 2016.

[3] Richard, M.K., and Sen, P.K., "Compact Fluorescent Lamps and their Effect on Power Quality and Application Guidelines”, IEEE Industry Applications Society Annual Meeting, Volume 1, No. 7 pp. 3-7, 2010.

[4] Eltamaly, A.M., "Power Quality Considerations of Heavy Loads of CFL on Distribution System”,IEEE International Symposium on Industrial Electronics, Volume 1632, No. 1638, pp. 27-30, 2011.

[5] Molina, J., and Sainz, L., "Model of Electronic Ballast Compact Fluorescent Lamps”,IEEE Transactions on Power Delivery, Volume 99,No. 1, 2014.

Nohra, A.F.H., Kanaan, H.Y., and Al-Haddad, K., “A Study on the Impact of a Massive Integration of Compact Fluorescent Lamps on Power Quality in Distribution Power Systems”,International Conference on Renewable Energies for Developing Countries, Volume 1, No. 6, pp. 28-29, 2012.

[7] Albu, M., Sanduleac, M., and Stanescu, C., "Syncretic Use of Smart Meters for Power Quality Monitoring in Emerging Networks”, IEEE Transactions on Smart Grid, No. 99, 2016. 
[8] Mollah, M.B., Islam M.R., and Islam, S.S., “The Forecasting Effects of Using Compact Fluorescent Lamps on Human Being, Environment and Electrical Power Quality in Bangladesh”, International Conference on Computer Communication and Informatics, 10-12 January, 2014.
[9] Silva, R.P.B.D., Brito, V.H.F., and Carvalho, E.O.P.D.,

"The Influence of Compact Fluorescent Lamp in Power Measurement and Billing”, IEEE Latin America Transactions, Volume 14, No. 4, April, 2016. 